\title{
Differential Expression of Cancer-Associated Fibroblast-Related Proteins in Ductal Carcinoma in situ According to Molecular Subtype and Stromal Histology
}

\author{
Ji Hee Lee Hye Min Kim Ja Seung Koo \\ Department of Pathology, Yonsei University College of Medicine, Seoul, South Korea
}

\author{
Keywords \\ Breast - Cancer-associated fibroblast - Ductal carcinoma in \\ situ $\cdot$ Stroma
}

\begin{abstract}
Objective: The purpose of this study is to investigate the expression of cancer-associated fibroblast (CAF)-related proteins and their implication in ductal carcinoma in situ (DCIS). Methods: We constructed a tissue microarray of 223 cases of DCIS and examined immunohistochemical staining for the 7 CAF-related proteins. We classified DCIS into luminal type, human epidermal growth factor receptor-2 (HER-2) type, and triple negative breast cancer (TNBC) according to the immunohistochemical results for estrogen receptor, progesterone receptor, and HER-2. We also classified DCIS into desmoplastic, normal-like, and inflammatory type according to stromal histology. Results: There were significant differences in the expression of S100A4, podoplanin, prolyl 4-hydroxylase subunit alpha 3, NG2, and PDGFRa in stromal cells of DCIS when classified according to molecular subtype. The expression rate of all CAF-related proteins in stromal cells was higher in the HER-2 type and TNBC than in the luminal type $(p<0.001)$. When classified according to stromal sub-
\end{abstract}

type, there were significant differences in the expression of all CAF-related proteins in stromal cells, with the inflammatory stromal type showing higher expression of CAF-related proteins than other stromal types. Conclusion: The expression of CAF-related proteins in stromal cells of DCIS varies according to molecular subtype and stromal type.

(c) 2018 S. Karger AG, Basel

\section{Introduction}

Ductal carcinoma in situ (DCIS) is a pre-invasive lesion of breast cancer. As normal epithelium progresses to atypical ductal hyperplasia, ductal carcinoma, and invasive carcinoma during the pathogenesis of breast cancer, DCIS might be considered a direct precursor of invasive carcinoma [1]. Also, approximately half of invasive carcinomas are accompanied by DCIS [1], and the nearly identical genetic changes of atypical ductal hyperplasia, ductal hyperplasia in situ, and invasive ductal carcinoma further support the notion that DCIS is a direct precursor of invasive carcinoma [2]. However, it is reported that only $20-50 \%$ of patients with untreated DCIS show progression to invasive carcinoma, suggesting that additional

\section{KARGER}

(c) 2018 S. Karger AG, Basel

E-Mail karger@karger.com

www.karger.com/pat
Ja Seung Koo, MD, $\mathrm{PhD}$

Department of Pathology

Yonsei University College of Medicine, Severance Hospital

50 Yonsei-ro, Seodaemun-gu, Seoul 120-752 (South Korea)

E-Mail kjs1976@yuhs.ac 
events are needed for DCIS to progress to invasive ductal carcinoma [3-5]. The factors required for DCIS to progress to invasive carcinoma might be intrinsic such as genetic alteration of tumor cells in DCIS and/or extrinsic, which include the effects of the tumor microenvironment or tumor stroma [6]. The tumor microenvironment consists of non-transformed elements located in the area of tumor but that are not tumor cells and includes immune system elements (such as macrophages and lymphocytes), blood vessel cells, fibroblasts, myofibroblasts, mesenchymal stem cells, adipocytes, and extracellular matrix. Among these, cancer-associated fibroblasts (CAFs) are the most important and have been widely studied [7]. It is reported that CAFs located around cancer cells are associated with tumor initiation, tumor-stimulatory inflammation, metabolism, metastasis, drug response, and immune surveillance [8]. CAFs have been shown to affect the initial progression of DCIS to invasive carcinoma through their interaction with cancer cells. There are various suggested markers of CAFs, such as $\alpha$-SMA [9], tenascin-C [10], chondroitin sulfate proteoglycan (NG2) [11], platelet-derived growth factor $\alpha$ receptor (PDGFR- $\alpha$ ) and PDGFR- $\beta$ [12], fibroblast activation protein (FAP) [13], podoplanin [14], prolyl 4-hydroxylase subunit alpha 3 (P4HA3) [15], and FSP-1 (S100A4) [11]. Therefore, we expect that there are different functional subtypes among CAFs. A recent research study divided CAFs into 4 subsets - FAP $\alpha$ type, FSP 1 type, PDGFR- $\alpha$ type, and PDGFR- $\beta$ type - and reported that each has distinct characteristics [16], supporting the hypothesis that CAFs have various phenotypes. However, there are no studies on the phenotypes of CAFs in DCIS. The purpose of this study is to investigate the expression of CAF-related proteins and their implications in DCIS.

\section{Materials and Methods}

\section{Patient Selection and Histologic Evaluation}

This study targeted patients who were diagnosed with DCIS and underwent surgery from January 2005 to December 2010 in Severance Hospital. Patients who previously underwent chemotherapy or hormonal therapy were excluded. The study was approved by the Institutional Review Board of Yonsei University Severance Hospital, which exempted the need for informed consent from patients. All cases were reviewed through hematoxylin and eosin (H\&E)-stained slides by a breast pathologist (J.S.K.). Histologic grade was assessed using the Nottingham grading system [17]. Clinicopathological parameters evaluated in each case included patient age at initial diagnosis, lymph node metastasis, tumor recurrence, distant metastasis, and patient survival. We classified the stromal type of DCIS through microscopic examination as follows: desmoplastic type, cellular fibroblast/myofibroblast proliferation; normal-like type, normal-like stromal feature without stromal reaction; inflammatory type, mainly inflammatory cells such as lymphocytes.

Tissue Microarray

A representative area showing tumor and tumor stroma was selected on the H\&E-stained slide, and a corresponding spot was marked on the surface of the paraffin block. Using a biopsy needle, the selected area was punched out, and a 3-mm tissue core was transferred to a $6 \times 5$ recipient block. Two tissue cores of the tumor were extracted to minimize extraction bias. Each tissue core was assigned a unique tissue microarray location number that was linked to a database containing other clinicopathological data.

\section{Immunohistochemistry}

The following antibodies were used for immunohistochemistry: S100A4, podoplanin, P4HA3, NG2, FAP-1, PDGFR- $\alpha$, PDGFR- $\beta$, estrogen receptor (ER), progesterone receptor (PR), human epidermal growth factor receptor-2 (HER-2), Ki-67. Immunohistochemistry was performed with formalin-fixed, paraffin-embedded tissue sections. Briefly, $5-\mu \mathrm{m}$-thick sections were obtained with a microtome, transferred onto adhesive slides, and dried at $62{ }^{\circ} \mathrm{C}$ for $30 \mathrm{~min}$. After incubation with primary antibodies, immunodetection was performed with biotinylated antimouse immunoglobulin, followed by peroxidase-labeled streptavidin using a labeled streptavidin biotin kit with 3,3'-diaminobenzidine chromogen as the substrate. The primary antibody incubation step was omitted in the negative control. Positive control tissue was used according to the manufacturer's recommendation. Slides were counterstained with Harris hematoxylin.

\section{Interpretation of Immunohistochemical Staining}

All immunohistochemical markers were assessed by using light microscopy. A cut-off value of $\geq 1 \%$ positively stained nuclei was used to define ER and PR positivity [18]. HER-2 staining was analyzed according to the American Society of Clinical Oncology/College of American Pathologists guidelines using the following categories: $0=$ no immunostaining; $1+=$ weak incomplete membranous staining in $<10 \%$ of tumor cells; $2+=$ complete membranous staining, either uniform or weak, in at least $10 \%$ of tumor cells; and $3+=$ uniform intense membranous staining in at least $30 \%$ of tumor cells [19]. HER-2 immunostaining was considered positive when strong $(3+)$ membranous staining was observed, whereas cases with 0 to $1+$ staining were regarded as negative. Cases showing 2+ HER-2 expression were evaluated for HER-2 amplification by fluorescent in situ hybridization.

Immunohistochemical markers for podoplanin, P4HA3, FAP $\alpha$, S100A4, PDGFR- $\alpha$, PDGFR- $\beta$, and NG2 were assessed by using light microscopy. The stained slides were evaluated semi quantitatively according to previously reported methods [20]. Tumor and stromal cell staining was assessed as 0 , negative or weak immunostaining in $<1 \%$ of the tumor/stroma; (1) focal expression in $1-10 \%$ of tumor/stroma; (2) positive in $11-50 \%$ of tumor/stroma; and (3) positive in $51 \% 100 \%$ of tumor/stroma. These evaluations were performed throughout the entire area of the tumor, and a score greater than 2 was considered positive.

\section{Tumor Phenotype Classification}

For this study, we classified phenotypes of DCIS according to the immunohistochemistry results for ER, PR, HER-2, Ki-67, and fluorescent in situ hybridization results for HER-2 as follows [21]: 
Table 1. Basal characteristics of ductal carcinoma in situ

\begin{tabular}{|c|c|c|c|c|c|}
\hline \multirow[t]{2}{*}{ Parameters } & \multirow{2}{*}{$\begin{array}{l}\text { Total }(n=223) \\
n(\%)\end{array}$} & \multicolumn{3}{|c|}{ Molecular subtype, $n(\%)$} & \multirow[t]{2}{*}{$p$ value } \\
\hline & & luminal $(n=126)$ & HER-2 $(n=84)$ & $\operatorname{TNBC}(n=13)$ & \\
\hline Age, years & & & & & 0.059 \\
\hline$\leq 50$ & $128(57.4)$ & $81(64.3)$ & $41(48.8)$ & $6(46.2)$ & \\
\hline$>50$ & $95(42.6)$ & $45(35.7)$ & $43(51.2)$ & $7(53.8)$ & \\
\hline Type & & & & & 0.004 \\
\hline Cribriform & $104(46.6)$ & $73(57.9)$ & $28(33.3)$ & $3(23.1)$ & \\
\hline Solid & $85(38.1)$ & $38(30.2)$ & $39(46.4)$ & $8(61.5)$ & \\
\hline Micropapillary & $23(10.3)$ & $9(7.1)$ & $12(14.3)$ & $2(15.4)$ & \\
\hline Papillary & $8(3.6)$ & $6(4.8)$ & $2(2.4)$ & $0(0.0)$ & \\
\hline Apocrine & $3(1.3)$ & $0(0.0)$ & $3(3.6)$ & $0(0.0)$ & \\
\hline Nuclear grade & & & & & 0.001 \\
\hline Low & $16(7.2)$ & $11(8.7)$ & $5(6.0)$ & $0(0.0)$ & \\
\hline Intermediate & $118(52.9)$ & $75(59.5)$ & $42(50.0)$ & $1(7.7)$ & \\
\hline High & $89(39.9)$ & $40(31.7)$ & $37(44.0)$ & $12(92.3)$ & \\
\hline Necrosis & & & & & $<0.001$ \\
\hline Absent & $106(47.5)$ & $78(61.9)$ & $23(27.4)$ & $5(38.5)$ & \\
\hline Focal & $35(15.7)$ & $22(17.5)$ & $11(13.1)$ & $2(15.4)$ & \\
\hline Comedo & $82(36.8)$ & $26(20.6)$ & $50(59.5)$ & $6(46.2)$ & \\
\hline Stromal type & & & & & $<0.001$ \\
\hline Desmoplastic & $142(63.7)$ & $96(76.2)$ & $41(48.8)$ & $5(38.5)$ & \\
\hline Sclerotic & $27(12.1)$ & $18(14.3)$ & $7(8.3)$ & $2(15.4)$ & \\
\hline Inflammatory & $54(24.2)$ & $12(9.5)$ & $36(42.9)$ & $6(46.2)$ & \\
\hline
\end{tabular}

Luminal A type, ER or/and PR positive, HER-2 negative, and Ki-67 labeling index $<14 \%$; Luminal B type, (HER-2 negative), ER or/and $\mathrm{PR}$ positive, HER-2 negative, and Ki-67 labeling index $\geq 14 \%$; HER2 overexpression type, ER and PR negative and HER-2 overexpressed or/and amplified; triple negative breast cancer (TNBC) type, ER, PR, and HER-2 all negative.

\section{Statistical Analysis}

Data were analyzed using SPSS for Windows, Version 12.0 (SPSS Inc., Chicago, IL, USA). For the determination of statistical significance, Student's $t$ and Fisher's exact tests were used for continuous and categorical variables, respectively. When analyzing data with multiple comparisons, a corrected $p$ value with application of the Bonferroni multiple comparison procedure was used. Statistical significance was set to $p<0.05$. Kaplan-Meier survival curves and log-rank statistics were employed to evaluate time to tumor recurrence and overall survival. Multivariate regression analysis was performed using the Cox proportional hazards model.

\section{Results}

\section{Basal Characteristics of DCIS}

Basal characteristics of the 223 cases of DCIS included in this study are shown in Table 1. Among 223 cases, 126 (56.5\%) were luminal type, 84 (37.7\%) were HER-2 type, and $13(5.8 \%)$ were TNBC. These molecular subtypes showed differences in histologic type $(p=0.004)$, nuclear grade $(p=0.001)$, necrosis pattern $(p<0.001)$, and stromal type $(p<0.001)$. In particular, the luminal type showed a high rate of cribriform type, no necrosis, and desmoplastic stromal type, whereas HER-2 and TNBC showed a high rate of solid type, comedo necrosis, and inflammatory stromal type.

\section{Expression of CAF-Related Proteins in DCIS}

According to Molecular Subtype

Immunohistochemical staining of CAF-related proteins showed positivity in tumor cells, fibroblasts, and immune cells in a case-by-case manner. Examination of the expression of CAF-related proteins according to molecular subtype in DCIS showed no difference in the expression in tumor cells (Table 2). However, the expression of CAF-related proteins - S100A4, podoplanin, P4HA3, NG2, and PDGFR - in stromal cell showed significant differences according to molecular subtype (Table 3 , and $p<0.001$ ). The expression of these 5 CAF-related proteins in stromal cells was higher in HER-2 type and TNBC than in luminal type (Fig. 1). For immunohistochemistry-positive stromal cells, positivity rate was higher in immune cells than in fibroblasts, except for PDGFR $\beta$. 
Table 2. CAF-related protein expression in tumor cells of ductal carcinoma in situ according to the molecular subtype

\begin{tabular}{|c|c|c|c|c|c|}
\hline Parameters & $\begin{array}{l}\text { Total }(n=223) \text {, } \\
n(\%)\end{array}$ & luminal $(n=126)$ & HER-2 $(n=84)$ & $\operatorname{TNBC}(n=13)$ & $p$ value \\
\hline Negative & $217(97.3)$ & $124(98.4)$ & $81(96.4)$ & $12(92.3)$ & \\
\hline Positive & $6(2.7)$ & $2(1.6)$ & $3(3.6)$ & $1(7.7)$ & \\
\hline Podoplanin & & & & & 0.349 \\
\hline P4HA3 & & & & & 0.191 \\
\hline Negative & $18(8.1)$ & $8(6.3)$ & $10(11.9)$ & $0(0.0)$ & \\
\hline Positive & 205 (91.9) & $118(93.7)$ & $74(88.1)$ & $13(100.0)$ & \\
\hline NG2 & & & & & 0.347 \\
\hline Negative & $28(12.6)$ & $13(10.3)$ & $12(14.3)$ & $3(23.1)$ & \\
\hline Positive & $195(87.4)$ & $113(89.7)$ & $72(85.7)$ & $10(76.9)$ & \\
\hline
\end{tabular}

Table 3. CAF-related protein expression in stromal cells of ductal carcinoma in situ according to the molecular subtype

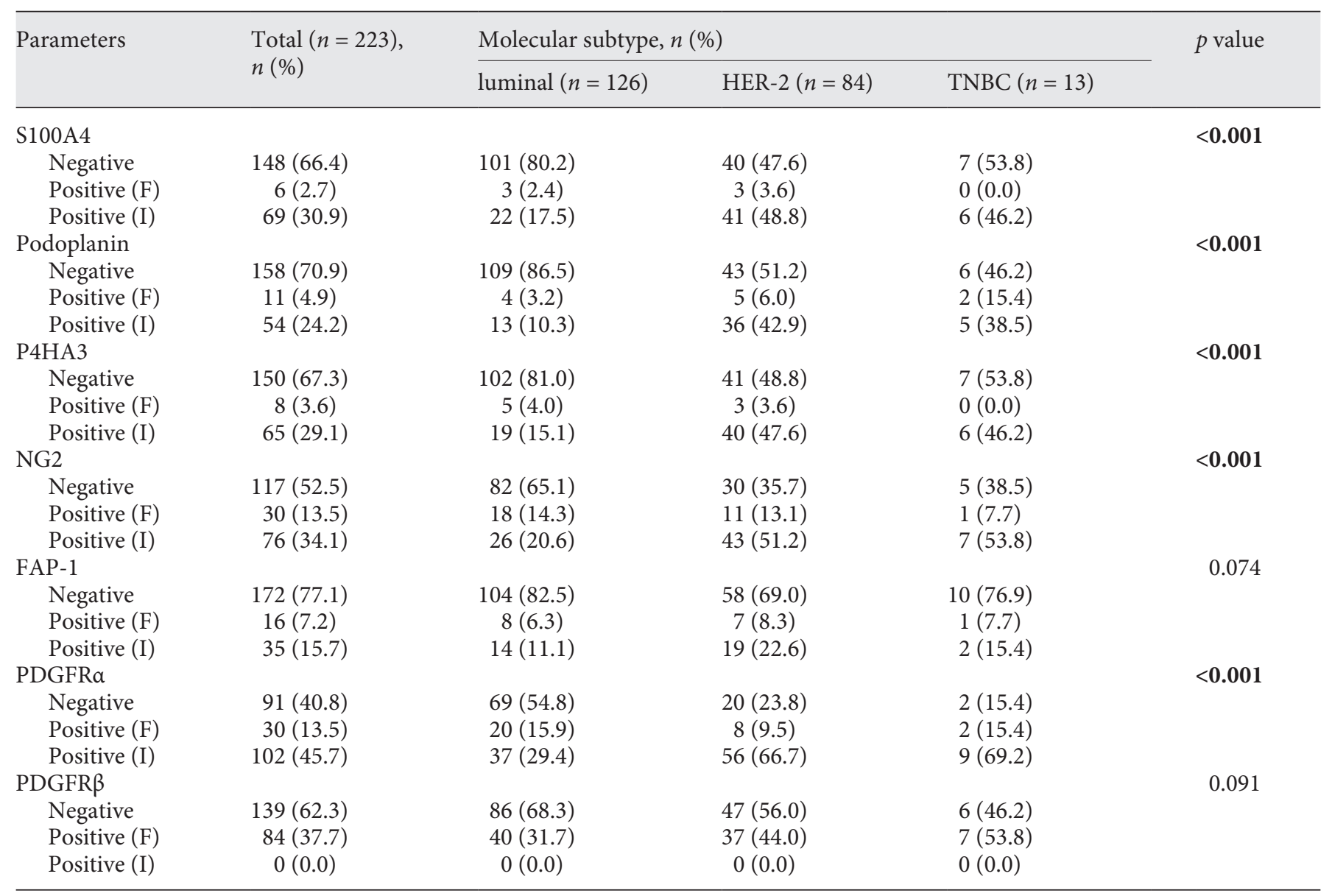

F, fibroblast, I, immune cell. 


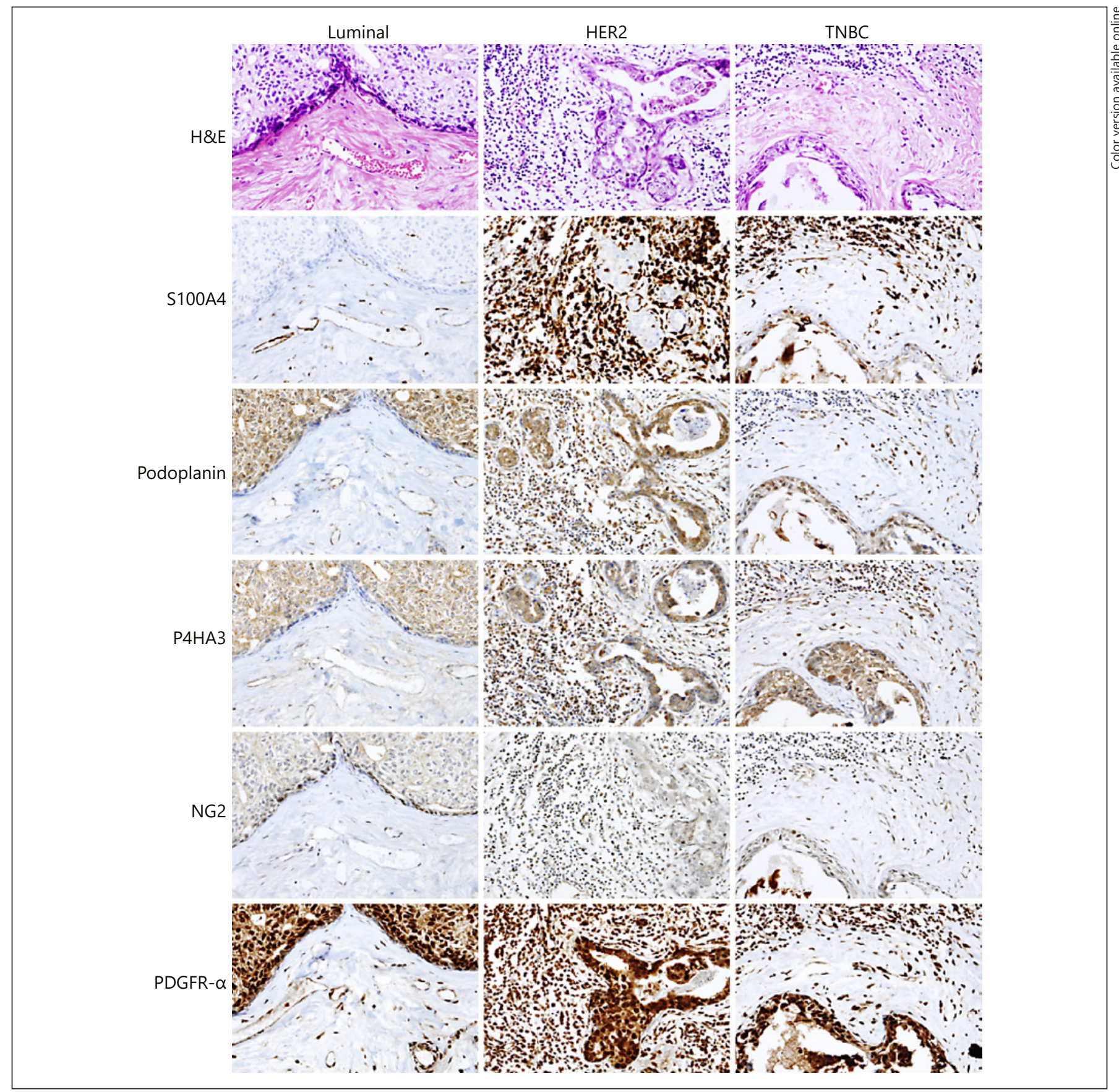

Fig. 1. Expression of CAF-related proteins in DCIS according to molecular subtype. The expression of CAF-related proteins - S100A4, podoplanin, P4HA3, NG2, and PDGFRa - was higher in HER-2 type and TNBC than in luminal type.

\section{Expression of CAF-Related Proteins in DCIS} According to Stromal Subtype

Examination of the expression of CAF-related proteins according to stromal subtype in DCIS showed no difference in the expression of tumor cells (Table 4). In contrast, the expression of all CAF-related proteins in stromal cells showed significant differences according to stromal subtype (Table 5). For all CAF-related proteins, the expression rate was higher in the inflammatory stromal type than in the other two stromal types (Fig. 2). 
Table 4. CAF-related protein expression in tumor cells of ductal carcinoma in situ according to the stromal subtype

\begin{tabular}{|c|c|c|c|c|c|}
\hline Parameters & $\begin{array}{l}\text { Total }(n=223) \\
n(\%)\end{array}$ & desmoplastic $(n=142)$ & normal-like $(n=27)$ & inflammatory $(n=54)$ & $p$ value \\
\hline Negative & $217(97.3)$ & $140(98.6)$ & $26(96.3)$ & $51(94.4)$ & \\
\hline Positive & $6(2.7)$ & $2(1.4)$ & $1(3.7)$ & $3(5.6)$ & \\
\hline Podoplanin & & & & & 0.396 \\
\hline P4HA3 & & & & & 0.312 \\
\hline Negative & $18(8.1)$ & $9(6.3)$ & $4(14.8)$ & $5(9.3)$ & \\
\hline Positive & $205(91.9)$ & $133(93.7)$ & $23(85.2)$ & $49(90.7)$ & \\
\hline NG2 & & & & & 0.688 \\
\hline Negative & $28(12.6)$ & $19(13.4)$ & $2(7.4)$ & $7(13.0)$ & \\
\hline Positive & $195(87.4)$ & $123(86.6)$ & $25(92.6)$ & $47(87.0)$ & \\
\hline
\end{tabular}

Table 5. CAF-related protein expression in stromal cells of ductal carcinoma in situ according to the stromal subtype

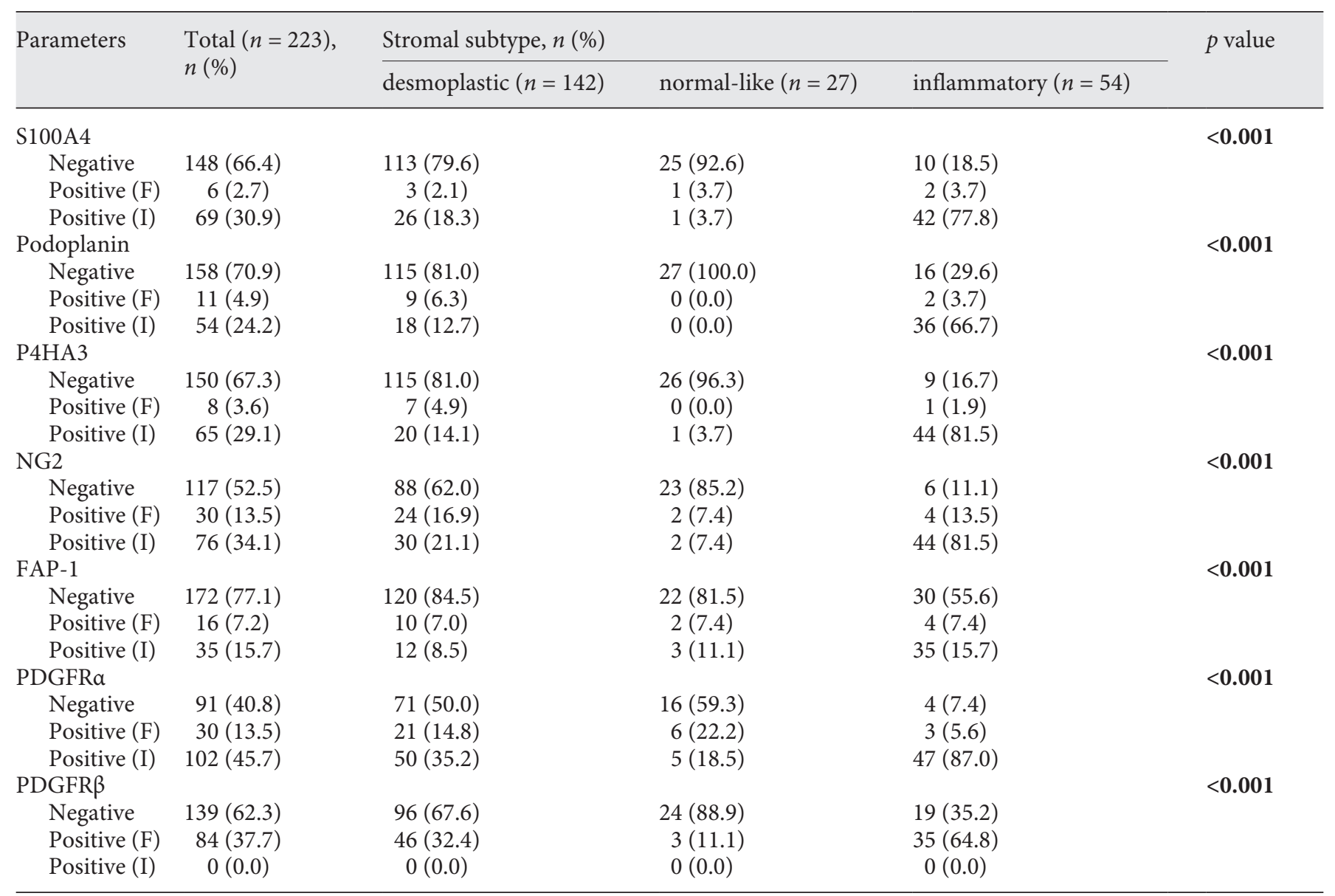

F, fibroblast, I, immune cell. 


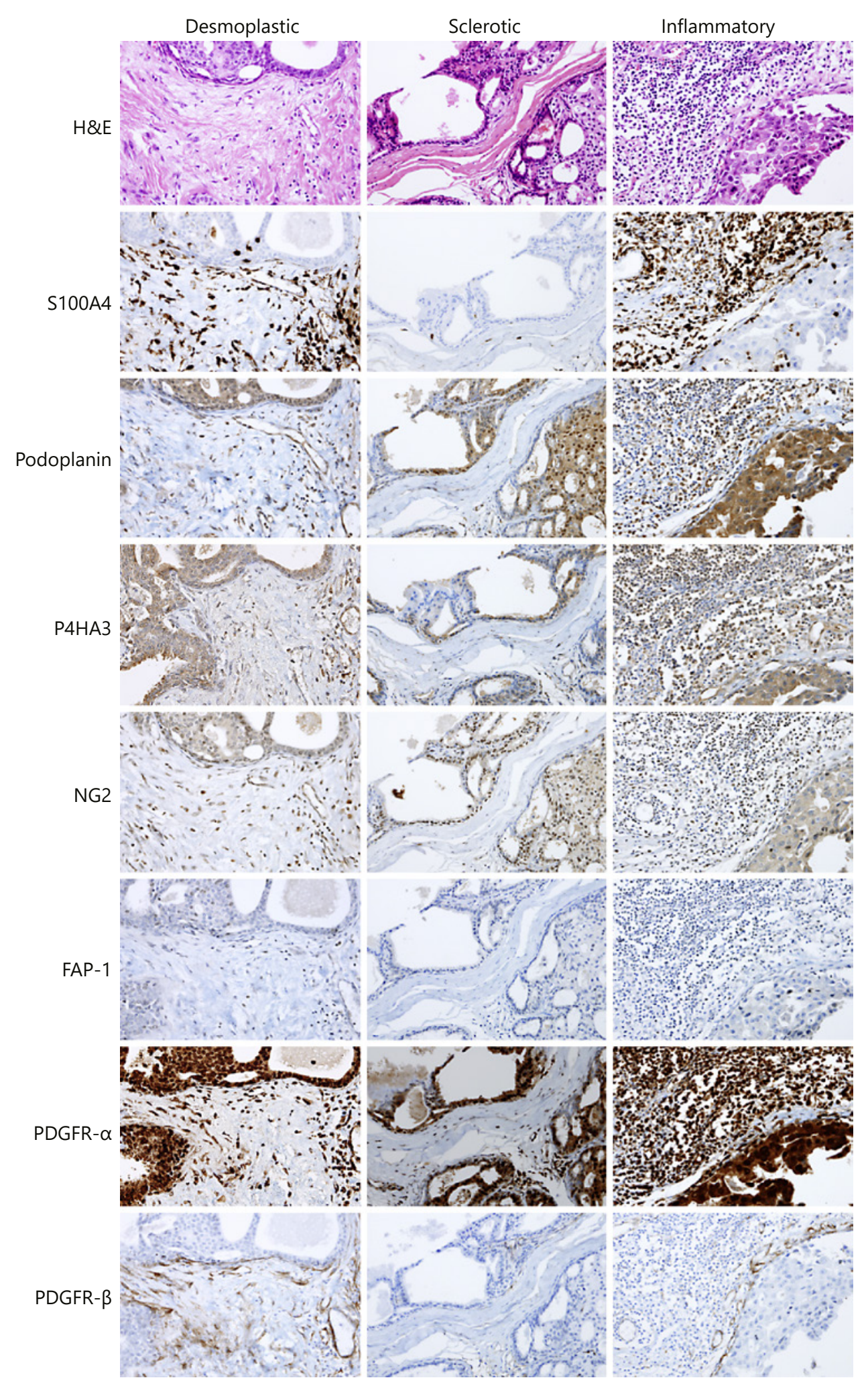

Fig. 2. Expression of CAF-related proteins in DCIS according to stromal subtype. The expression of all CAF-related proteins in stromal cells was higher in the inflammatory stromal type than in the other two stromal types.

CAF Proteins in DCIS According to Molecular Subtype and Stromal Histology
Pathobiology 2018;85:311-321

DOI: $10.1159 / 000492392$ 


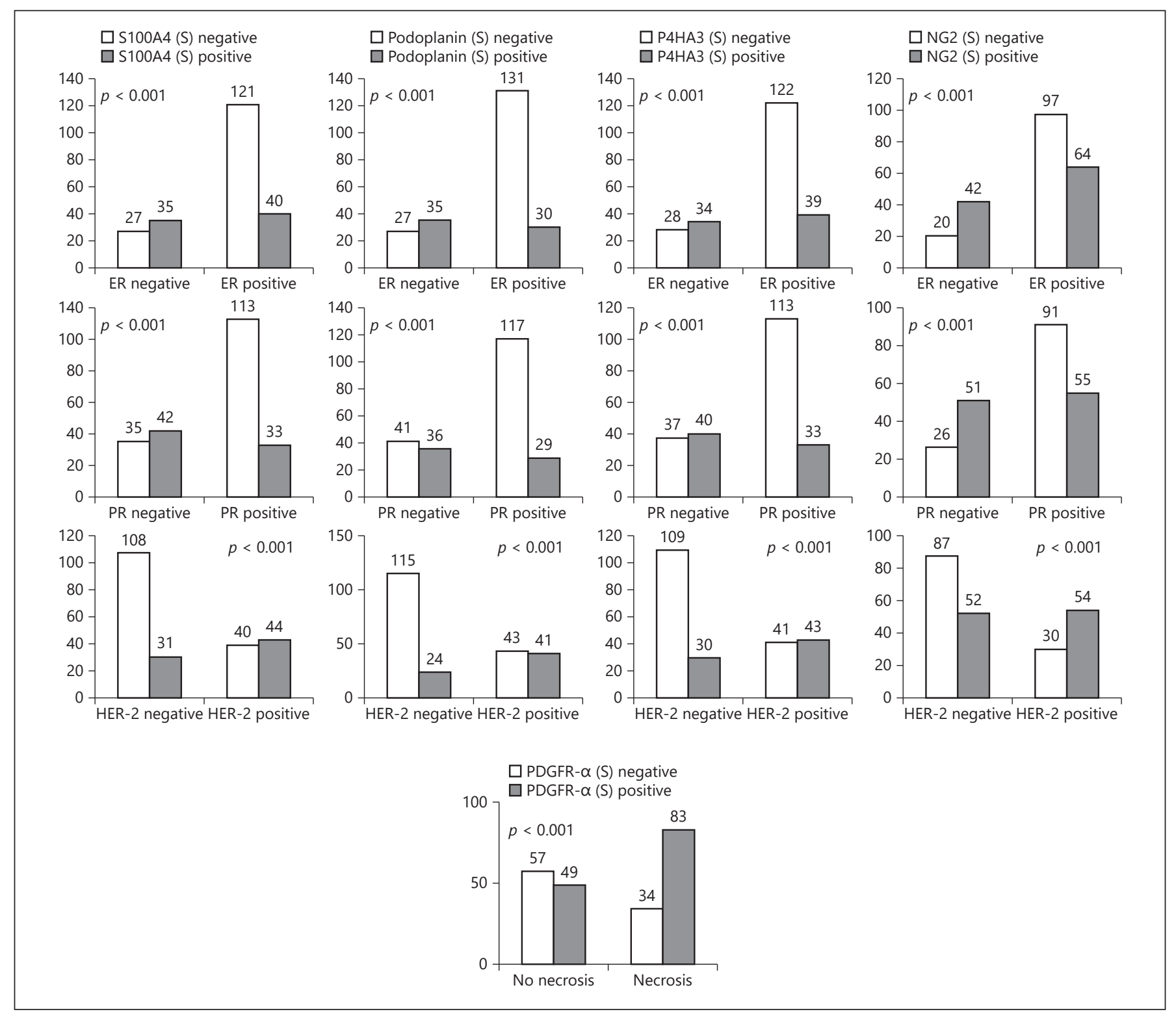

Fig. 3. Correlations between clinicopathological factors and expression of CAF-related proteins. Stromal PDGFR- $\alpha$ positivity showed a significant association with tumor cell necrosis. In addition, S100A4 positivity, podoplanin positivity, P4HA3 positivity, and NG2 positivity in stromal cells was associated with ER negativity, PR negativity, and HER-2 positivity.

For immunohistochemistry-positive stromal cells, positivity rate was higher in immune cells than in fibroblasts.

\section{Correlations between Clinicopathological Factors and Expression of CAF-Related Proteins}

Analysis of the association between the expression of CAF-related proteins and clinicopathological factors revealed that PDGFR- $\alpha$ positivity in stromal cells was associated with tumor cell necrosis $(p<0.001)$. S100A4 pos- itivity, podoplanin positivity, $\mathrm{P} 4 \mathrm{HA} 3$ positivity, and NG2 positivity in stromal cells were associated with ER negativity, PR negativity, and HER-2 positivity, respectively $(p<0.001$, Fig. 3$)$.

\section{Impact of CAF-Related Proteins in DCIS on Prognosis}

In univariate analysis of the effect of CAF-related proteins in patients with DCIS on disease-free survival, there was no factor that showed statistical significance. 


\section{Discussion}

We investigated the expression of CAF-related proteins in DCIS. Our study showed differences in the expression of CAF-related proteins (S100A4, podoplanin, P4HA3, NG2, and PDGFR- $\alpha$ ) in the stromal component of DCIS according to molecular subtype. Specifically, the expression rate was higher in HER-2 type and TNBC than in luminal type. As molecular subtypes of invasive breast cancer differ from one another in clinical, histological, molecular, and therapeutic aspects, we conclude that cancer cells of different molecular subtypes have different characteristics $[22,23]$. It is reported that DCIS also has different tumor biology, according to its molecular subtype [24-26]. Therefore, there appears to be cross talk between cancer cells and tumor stroma through several signaling pathways. Because such cross talks affect the tumor microenvironment [27], we hypothesize that characteristics of the tumor stroma would also be different according to molecular subtype of DCIS, as confirmed through this study. Previous studies also reported different expressions of CAF genes in different molecular subtypes of breast cancer [28]. They reported that the expression of genes associated with cancer cell migration was higher in HER-2 type CAFs than in ER-positive type CAFs, similar to the results of this study. The functional pathways of genes of which expression increased in CAFs of HER-2 positive breast cancer were actin cytoskeleton signaling and integrin signaling. It has been reported that actin cytoskeleton signaling is associated with NG2 [29] and PDGFR [30], while integrin signaling is associated with S100A4 [31-33] and NG2 [34-36]. It has also been reported that molecular features that induce disease progression are different in each intrinsic molecular subtype of DCIS [24] and have an important role in the tumor microenvironment and progression of DCIS [37, 38]. CAF-related proteins also have an intrinsic function. Each CAF-related protein has an association with each function as follows: FAP-1; extracellular matrix modulation and cell invasion, S100A4; metastatic colonization, PDGFR- $\alpha$; tumorcell growth and angiogenesis, PDGFR- $\beta$; metastatic spread, and NG2; tumor cell invasion and metastasis [16]. Therefore, it is possible that differences in the expression of CAF-related proteins in stromal cells of DCIS affect disease progression according to the intrinsic subtype, and further study is needed to address this.

In this study, the expression of all CAF-related proteins in the stromal component was different according to the histological phenotype in the order of inflammatory type $>$ desmoplastic type $>$ normal-like type. One possible

CAF Proteins in DCIS According to

Molecular Subtype and Stromal Histology mechanism for the different expression of CAF-related proteins by stromal histologic phenotype is the influence of molecular subtype. HER-2 type and TNBC DCIS had a high proportion of inflammatory stroma. Previous studies also showed frequent stromal inflammation in HER-2 positive DCIS [25] and a high expression ratio of immune response-related genes in basal type DCIS [24]. Therefore, we suggest that the molecular subtype of DCIS can affect the stromal histology. Another possible mechanism is the correlation between CAF-related proteins and immune cells. It has been reported that FAPa is associated with immunomodulatory function [16], S100A4 induces massive infiltration of immune cells through serum amyloid A in breast cancer [39], and NG2 induces macrophage recruitment in brain tumor [40]. These results indicate that College of American Pathologists-related proteins are associated with immune reaction. This study also shows that CAF-related proteins are expressed not only in stromal fibroblasts, but also in immune cells. The higher expression rate of immune cells compared to that of stromal fibroblasts supports the relationship between CAF-related proteins and immune cells.

In this study, the expression of CAF-related proteins showed no association with the prognosis of DCIS. A previous study of mammary invasive carcinoma reported that tumoral S100A4 negativity and stromal S100A4 positivity were associated with poor prognosis [41]. However, there is a difficulty in the statistical analysis of DCIS owing to the lack of recurrence or death. A multi-center study would be suitable for investigating associations with prognosis of DCIS.

In conclusion, our study showed different expressions of CAF-related proteins in stroma according to molecular subtype and stromal type of DCIS. The expression of CAF-related proteins was higher in HER-2 type and TNBC than in luminal type and was also higher in inflammatory stromal type than in other stromal types.

\section{Acknowledgements}

This study was supported by a grant from the National R\&D Program for Cancer Control, Ministry of Health \& Welfare, and Republic of Korea (1420080). This research was supported by Basic Science Research Program through the National Research Foundation of Korea (NRF) funded by the Ministry of Science, ICT and Future Planning (2015R1A1A1A05001209).

\section{Disclosure Statement}

The authors declare no conflicts of interest. 


\section{References}

1 Doebar SC, van den Broek EC, Koppert LB, Jager A, Baaijens $\mathrm{MH}$, Obdeijn IM, van Deurzen CH: Extent of ductal carcinoma in situ according to breast cancer subtypes: a population-based cohort study. Breast Cancer Res Treat 2016;158:179-187.

2 Gao Y, Niu Y, Wang X, Wei L, Lu S: Genetic changes at specific stages of breast cancer progression detected by comparative genomic hybridization. J Mol Med (Berl) 2009;87:145152.

3 Page DL, Dupont WD, Rogers LW, Landenberger M: Intraductal carcinoma of the breast: follow-up after biopsy only. Cancer 1982;49: 751-758.

4 Sanders ME, Schuyler PA, Dupont WD, Page DL: The natural history of low-grade ductal carcinoma in situ of the breast in women treated by biopsy only revealed over 30 years of long-term follow-up. Cancer 2005; 103: 2481-2484.

5 Page DL, Dupont WD, Rogers LW, Jensen RA, Schuyler PA: Continued local recurrence of carcinoma 15-25 years after a diagnosis of low grade ductal carcinoma in situ of the breast treated only by biopsy. Cancer 1995;76: 1197-1200.

6 Cowell CF, Weigelt B, Sakr RA, Ng CK, Hicks J, King TA, Reis-Filho JS: Progression from ductal carcinoma in situ to invasive breast cancer: revisited. Mol Oncol 2013;7:859-869.

7 Franco OE, Shaw AK, Strand DW, Hayward SW: Cancer associated fibroblasts in cancer pathogenesis. Semin Cell Dev Biol 2010;21: 33-39.

8 Ostman A: Cancer-associated fibroblasts: recent developments and emerging challenges. Semin Cancer Biol 2014;25:1-2.

9 Desmouliere A, Guyot C, Gabbiani G: The stroma reaction myofibroblast: a key player in the control of tumor cell behavior. Int J Dev Biol 2004;48:509-517.

10 De Wever O, Nguyen QD, Van Hoorde L, Bracke M, Bruyneel E, Gespach C, Mareel M: Tenascin-c and sf/hgf produced by myofibroblasts in vitro provide convergent pro-invasive signals to human colon cancer cells through rhoa and rac. FASEB J 2004; 18:10161018.

11 Sugimoto H, Mundel TM, Kieran MW, Kalluri R: Identification of fibroblast heterogeneity in the tumor microenvironment. Cancer Biol Ther 2006;5:1640-1646.

12 Pietras K, Sjoblom T, Rubin K, Heldin CH, Ostman A: PDGF receptors as cancer drug targets. Cancer Cell 2003;3:439-443.

13 Kraman M, Bambrough PJ, Arnold JN, Roberts EW, Magiera L, Jones JO, Gopinathan A, Tuveson DA, Fearon DT: Suppression of antitumor immunity by stromal cells expressing fibroblast activation protein-alpha. Science 2010;330:827-830.

14 Kawase A, Ishii G, Nagai K, Ito T, Nagano T, Murata Y, Hishida T, Nishimura M, Yoshida J, Suzuki K, Ochiai A: Podoplanin expression by cancer associated fibroblasts predicts poor prognosis of lung adenocarcinoma. Int J Cancer 2008;123:1053-1059.

15 Kojima Y, Acar A, Eaton EN, Mellody KT, Scheel C, Ben-Porath I, Onder TT, Wang ZC, Richardson AL, Weinberg RA, Orimo A: Autocrine tgf-beta and stromal cell-derived factor-1 (SDF-1) signaling drives the evolution of tumor-promoting mammary stromal myofibroblasts. Proc Natl Acad Sci U S A 2010; 107:20009-20014.

16 Cortez E, Roswall P, Pietras K: Functional subsets of mesenchymal cell types in the tumor microenvironment. Semin Cancer Biol 2014;25:3-9.

17 Elston CW, Ellis IO: Pathological prognostic factors in breast cancer. I. The value of histological grade in breast cancer: experience from a large study with long-term follow-up. Histopathology 1991;19:403-410.

18 Hammond ME, Hayes DF, Dowsett M, Allred DC, Hagerty KL, Badve S, Fitzgibbons PL, Francis G, Goldstein NS, Hayes M, Hicks DG, Lester S, Love R, Mangu PB, McShane L, Miller K, Osborne CK, Paik S, Perlmutter J, Rhodes A, Sasano H, Schwartz JN, Sweep FC, Taube S, Torlakovic EE, Valenstein P, Viale G, Visscher D, Wheeler T, Williams RB, Wittliff JL, Wolff AC: American society of clinical oncology/college of american pathologists guideline recommendations for immunohistochemical testing of estrogen and progesterone receptors in breast cancer. J Clin Oncol 2010;28:2784-2795.

19 Wolff AC, Hammond ME, Schwartz JN, Hagerty KL, Allred DC, Cote RJ, Dowsett M, Fitzgibbons PL, Hanna WM, Langer A, McShane LM, Paik S, Pegram MD, Perez EA, Press MF, Rhodes A, Sturgeon C, Taube SE, Tubbs R, Vance GH, van de Vijver M, Wheeler TM, Hayes DF: American society of clinical oncology/college of american pathologists guideline recommendations for human epidermal growth factor receptor 2 testing in breast cancer. J Clin Oncol 2007; 25:118-145.

20 Henry LR, Lee HO, Lee JS, Klein-Szanto A Watts P, Ross EA, Chen WT, Cheng JD: Clinical implications of fibroblast activation protein in patients with colon cancer. Clin Cancer Res 2007;13:1736-1741.

21 Goldhirsch A, Wood WC, Coates AS, Gelber RD, Thurlimann B, Senn HJ: Strategies for subtypes - dealing with the diversity of breast cancer: highlights of the st. Gallen international expert consensus on the primary therapy of early breast cancer 2011. Ann Oncol 2011;22:1736-1747.

22 Perou CM, Sorlie T, Eisen MB, van de Rijn M, Jeffrey SS, Rees CA, Pollack JR, Ross DT, Johnsen H, Akslen LA, Fluge O, Pergamenschikov A, Williams C, Zhu SX, Lonning PE, Borresen-Dale AL, Brown PO, Botstein D: Molecular portraits of human breast tumours. Nature 2000;406:747-752.
23 Sorlie T, Perou CM, Tibshirani R, Aas T, Geisler S, Johnsen H, Hastie T, Eisen MB, van de Rijn M, Jeffrey SS, Thorsen T, Quist H, Matese JC, Brown PO, Botstein D, Eystein Lonning P, Borresen-Dale AL: Gene expression patterns of breast carcinomas distinguish tumor subclasses with clinical implications. Proc Natl Acad Sci U S A 2001;98:1086910874.

24 Lesurf R, Aure MR, Mork HH, Vitelli V, Lundgren S, Borresen-Dale AL, Kristensen V, Warnberg F, Hallett M, Sorlie T: Molecular features of subtype-specific progression from ductal carcinoma in situ to invasive breast cancer. Cell Rep 2016;16:1166-1179.

25 Van Bockstal $M$, Lambein $K$, Denys $H$, Braems G, Nuyts A, Van den Broecke R, Cocquyt V, De Wever O, Libbrecht L: Histopathological characterization of ductal carcinoma in situ (DCIS) of the breast according to HER2 amplification status and molecular subtype. Virchows Arch 2014;465:275-289.

26 VandenBussche CJ, Elwood H, CiminoMathews A, Bittar Z, Illei PB, Warzecha HN: Clinicopathologic features of ductal carcinoma in situ in young women with an emphasis on molecular subtype. Hum Pathol 2013;44: 2487-2493.

27 De Wever O, Mareel M: Role of tissue stroma in cancer cell invasion. J Pathol 2003;200: 429-447.

28 Tchou J, Kossenkov AV, Chang L, Satija C, Herlyn M, Showe LC, Pure E: Human breast cancer associated fibroblasts exhibit subtype specific gene expression profiles. BMC Med Genomics 2012;5:39.

29 Lin XH, Dahlin-Huppe K, Stallcup WB: Interaction of the NG2 proteoglycan with the actin cytoskeleton. J Cell Biochem 1996;63:463477.

30 Theisen CS, Wahl JK 3rd, Johnson KR, Wheelock MJ: NHERF links the n-cadherin/catenin complex to the platelet-derived growth factor receptor to modulate the actin cytoskeleton and regulate cell motility. Mol Biol Cell 2007; 18:1220-1232.

31 Chen M, Sinha M, Luxon BA, Bresnick AR, O'Connor KL: Integrin alpha6beta4 controls the expression of genes associated with cell motility, invasion, and metastasis, including s100a4/metastasin. J Biol Chem 2009;284: 1484-1494.

32 Chen PS, Wang MY, Wu SN, Su JL, Hong CC, Chuang SE, Chen MW, Hua KT, Wu YL, Cha ST, Babu MS, Chen CN, Lee PH, Chang KJ, Kuo ML: CTGF enhances the motility of breast cancer cells via an integrin-alphavbeta3-ERK1/2-dependent s100a4-upregulated pathway. J Cell Sci 2007;120:2053-2065.

33 Kim TH, Kim HI, Soung YH, Shaw LA, Chung J: Integrin (alpha6beta4) signals through SRC to increase expression of s100a4, a metastasis-promoting factor: implications for cancer cell invasion. Mol Cancer Res 2009; 7:1605-1612. 
34 Chekenya M, Krakstad C, Svendsen A, Netland IA, Staalesen V, Tysnes BB, Selheim F, Wang J, Sakariassen PO, Sandal T, Lonning PE, Flatmark T, Enger PO, Bjerkvig R, Sioud M, Stallcup WB: The progenitor cell marker NG2/MPG promotes chemoresistance by activation of integrin-dependent pi3k/akt signaling. Oncogene 2008;27:5182-5194.

35 Fukushi J, Makagiansar IT, Stallcup WB: NG2 proteoglycan promotes endothelial cell motility and angiogenesis via engagement of galectin- 3 and alpha3betal integrin. Mol Biol Cell 2004;15:3580-3590.

36 Stallcup WB: NG2 proteoglycan enhances brain tumor progression by promoting beta-1 integrin activation in both CIS and trans orientations. Cancers (Basel) 2017;9.
37 Hendry S, Pang JB, Byrne DJ, Lakhani SR, Cummings MC, Campbell IG, Mann GB, Gorringe KL, Fox SB: Relationship of the breast ductal carcinoma in situ immune microenvironment with clinicopathological and genetic features. Clin Cancer Res 2017;23: 5210-5217.

38 Sameni M, Cavallo-Medved D, Franco OE, Chalasani A, Ji K, Aggarwal N, Anbalagan A, Chen X, Mattingly RR, Hayward SW, Sloane BF: Pathomimetic avatars reveal divergent roles of microenvironment in invasive transition of ductal carcinoma in situ. Breast Cancer Res 2017;19:56.

39 Hansen MT, Forst B, Cremers N, Quagliata L, Ambartsumian N, Grum-Schwensen B, Klingelhofer J, Abdul-Al A, Herrmann P, Os- terland M, Stein U, Nielsen GH, Scherer PE, Lukanidin E, Sleeman JP, Grigorian M: A link between inflammation and metastasis: serum amyloid $\mathrm{A} 1$ and $\mathrm{A} 3$ induce metastasis, and are targets of metastasis-inducing s100a4. Oncogene 2015;34:424-435.

40 Cejudo-Martin P, Kucharova K, Stallcup WB: Role of NG2 proteoglycan in macrophage recruitment to brain tumors and sites of CNS demyelination. Trends Cell Mol Biol 2016;11: 55-65.

41 Park SY, Kim HM, Koo JS: Differential expression of cancer-associated fibroblast-related proteins according to molecular subtype and stromal histology in breast cancer. Breast Cancer Res Treat 2015;149: 727-741. 